\title{
Analysis of Using MLE in Moodle for Campus-Wide Environment
}

\author{
Ajay Arunachalam and Lakshmi Kurup
}

\begin{abstract}
Today mobile learning has become the heir of electronic learning. M-Learning technologies are a perfect complement to Open and Distance Learning (ODL), allowing communication with learners beyond their traditional places of learning. In this paper we are using MLE in Moodle environment to facilitate integrated teaching Management in our institution. Mobile learning (M-Learning) integrates the current mobile and wireless computing technology with education, primarily to enhance the effectiveness of the traditional learning process. One of the difficulties in implementing M-Learning is to deliver the content efficiently. This paper describes the steps in development of M-Learning management tool in campus-wide environment with authentic\& proper security features. We have customized the Moodle Learning Managements System as per the institute requirement by modifying the configuration files and source files. We have proposed the steps using which one can configure MLE-Moodle at ease. After the practical implementation for about one year long time, it is illustrated that this platform can effectively facilitate the information communication and sharing, the information literary development of teachers and students and the building of network courses.
\end{abstract}

Index Terms-Moodle, institution, integrated teaching management, MLE, VLE, LMS, MLE-Moodle.

\section{INTRODUCTION}

M-Learning technologies can potentially deliver education at significantly reduced costs by leveraging the relatively cheap mobile infrastructure available throughout the world. Mobile devices also have a strong appeal among the students that can be exploited to provide flexible learning opportunities regardless of the time or the location of learners. Research has proved that mobile learning is successful in enhancing learning and promoting both individualized and collaborative learning. Yet, mobile learning was not successful in making the transition from the experimental and pilot studies phase to the large scale and common us e phase. MLE-Moodle is an out-of-the-box mobile Learning (M-Learning) system, designed for mobile Phones. It is realized as a plug-in for the open-source Learning Management System (LMS) Moodle.

\section{IMPORTANCE OF MOODLE}

Moodle is a software package for producing Internet based courses and web sites. The acronym MOODLE stands for Modular Object-Oriented Dynamic Learning

Manuscript received October 13, 2012; revised November 28, 2012.

The authors are with D. J Sanghvi College of Engineering, Mumbai, India (e-mail: ajay.arunachalam@djsce.ac.in, lakshmi.kurup@djsce.ac.in).
Environment [5]. It's an ongoing development project designed to support a social constructionist framework of education. Moodle is provided freely as Open Source software (under the GNU Public License) [10]. Moodle is also known as a Course Management System, Learning Management System, or Virtual Learning Environment (VLE), thereby emphasizing more learner-centered activity and system interactivity for remote learners than traditional classroom students [11]. Virtual learning environments appear to offer a number of benefits :such as: anytime, anywhere access, improved motivation, access to higher or novel learning styles, opportunities for independent learning, better integration of information and communication technology (ICT) tools, and increased parental engagement[3]. Moodle has several features typical of an elearning platform, plus some original innovations (like its filtering system) [1]. Moodle is very similar to a learning management system, but it has many more standard features. Moodle can be used in many types of environments such as in education, training and development, and business settings. Developers can extend Moodle's modular construction by creating plugins for specific new functionality. Moodle's infrastructure supports many types of plug-ins:

- Activities (including word and math games)

- Resource types

- Question types (multiple choice, true and false, fill in the blank, etc)

- $\quad$ Data field types (for the database activity)

- Graphical themes

- Authentication methods (can require username and password accessibility)

- Enrollment methods

- Content filters

Moodle also has several contributed modules, including SCORM, WebQuest and the Document Management System[4], wiki, blogs[7], Forums, e-Assessment, e-portfolios which aims to further establish Moodle as the leading open source VLE[9].

\section{Steps to Configure MoOdLE}

\section{A. Preparing Your Server}

Moodle is meant to be run on a server. It requires

Apache2, the PHP scripting language, and a database (either

MySQL or postgreSQL). We preferred MySQL. A LAMP server (Linux, Apache2, MySQL, PHP) can easily be installed from the command-line interface:

- sudo tasksel install lamp-server 
When installing the LAMP server, note the MySQL root password carefully. This will be required during Moodle installation.

Moodle must know where the server is located. The FQDN (Fully Qualified Domain Name) refers to the location of the server on which the Moodle database is located. In general, there are two options: localhost (meaning the database will be located on the same computer on which Moodle will be installed) or a URL.

Needless to worry, whichever option you choose can be changed later. For initial installation, it is easiest to use localhost as the FQDN (and also wherever it is available as an installation option).

\section{B. Installing Ubuntu}

- Download and burn an Ubuntu 8.04 LTS server CD to a Live CD.

- $\quad$ Start the computer and boot from the Live CD.

- $\quad$ Select Install to hard drive.

- $\quad$ Select your language, country, and keyboard layout (i.e. English, United States, American English)

- Select manually configure and set an IP address (or autoconfig if you don't know).

- $\quad$ Enter your servername (i.e. moodletest)

- Select to manually edit the partition tableSelect your timezone. (i.e. Central)

- $\quad$ Set clock to Universal Time.

- Enter Administrators full name.

- Enter account name

- Enter a secure password.

- Reboot.

- $\quad$ Log in using your account name/password.

\section{Installing the Packages}

Edit the /etc/apt/sources.list file. Remove the \# mark on lines 22 and 38 to enable access to the universe package source and universe security updates. You will need to reenter your account password when sudo asks for it.

- $\quad$ sudo nano /etc/apt/sources.list

D. Installing the security updates

- $\quad$ sudo apt-get update

- $\quad$ sudo apt-get dselect-upgrade

- $\quad$ Sudo reboot

\section{E. Install Apache and PHP5}

- $\quad$ sudo apt-get install apache2 libapache2-mod-php5 php5-gd

- $\quad$ sudo apt-get install libapache2-mod-security php5ldap php5-odbc

- Restart Apache using sudo /etc/init.d/apache2 restart

F. Install MySQL

- $\quad$ sudo apt-get install mysql-server php5-mysql

- Replace the following string NewRootDatabasePassword with a secure password of your own choosing.

- Create the Moodle database and Moodle user in MySQL.

mysql $-\mathbf{u}$ root $-\mathrm{p}$

$>$ CREATE DATABASE moodle DEFAULT CHARACTER SET utf8 COLLATE utf8_unicode_ci;

$>$ GRANT ALL PRIVILEGES ON moodle.* TO moodleuser@localhost IDENTIFIED BY

'NewMoodleDatabasePassword

;

$>$ FLUSH PRIVILEGES;

$>$ QUIT

\section{G. Installing Moodle}

Install the Moodle package from the command-line interface and follow the prompts: sudo apt-get install moodle

Database server software for Moodle: mysql-server

$->$ follow remainder of instructions. Assuming the

database is hosted on the same computer as the one

Moodle is being installed upon, accept localhost for the options when prompted.

- $\quad$ Edit Moodle configuration options[2] sudo nano /etc/moodle/config.php

- Edit Moodle apache2 configuration sudo nano /etc/moodle/apache.conf

Finish installation through a web browser http://localhost/moodle

H. Allow Access to your Moodle from other Computers

- This moodle install will only work from the localhost. To make it accessible from other hosts you must edit the file /etc/apache2/conf.d/moodle.

- $\quad$ Type

- $\quad$ sudo nano /etc/apache2/conf.d/moodle

- About 10 lines down you see the following line \#allow from all

- The \# indicates it is commented out, so remove the \# and use CTRL+O to save the file.

- $\quad$ Now restart apache by typing

- $\quad$ sudo /etc/init.d/apache2 restart in the terminal.

You should now be able to access the moodle from other hosts by doing http://<address of your moodle host $>$ /moodle.

\section{I. $\quad$ Upgrading Moodle 1.8 to Moodle 1.9}

- $\quad$ Stop your moodle 1.8 (mantainence mode)

- Copy your moodle DB

- Copy your Moodle 1.8 code to the directory where you'll be installing 1.9:

- $\quad$ cp /usr/share/moodle18 /usr/share/moodle19

- Switch to the 1.9 directory and get the new version of Moodle:

- cd /var/www/path2moodle19 | wget http://download.moodle.org/stable19/moodleweekly-19.tgz

- Un-compress the new Moodle 1.9 files: tar xvzf moodle-weekly-19.tgz

- Move the files from the moodle subfolder into your 1.9 folder: cp moodle/* . - a

- $\quad$ Remove the now-empty Moodle folder: rm moodle Rf

- Visit your moodle notifications page and follow the wizard.

\section{Requirements to Prepare Your Mle-Moodle SERVER}

MLE-Moodle is an extension to Moodle, so you need to install Moodle 1.9.x first. Therefore the requirements of 
Moodle are the requirements of MLE-Moodle too:

- $\quad$ Moodle 1.9.x

- $\quad$ PHP 4.3 .0

- Database: MySQL 4.1.16 or Postgres 8.0 or MSSQL 9.0 or Oracle 9.0

\section{A. Setting up Moodle Courses}

So after you have finished the installation of Moodle, you should create at least one course. So as the Admin do the following:

- In the "Site Administration" panel click on "Courses" and "Add/edit courses"

- Click on the "Add a new course"

- Select a Full name like "mLearning Testing course" and a short name like "mLearn

- $\quad$ On the next page (assigning roles) add yourself as a teacher, so you can access the course

If you want you can click on your "mLearning Testing course" and add learning content. You can do this by pressing the "Turn editing on"-button, which is loacted at the upper right. Afterwards you can add resources and learningactivities.

\section{B. Installing MLE-Moodle Files:}

Now we are ready to turn Moodle to a mLearning system.

- $\quad$ Download the MLE-Moodle installation package.

- Extract the content and upload this content (the content of a folder named "moodle" in the ZIP file!) to the moodle root- folder on your web-server.

- To check if you were successful, go to the "blocks" folder in the Moodle root-folder. You should see a new folder called "mle".

\section{Finishing the Installing}

Now visit your Moodle web-server with your webbrowser and log-in as the admin.

- In the "Site Administration" panel click on "Notifications"

- After the page has finished loading click on the "Continue" button at the bottom of the page. Click on the "Save" button if you are asked.

- In the "Site Administration" panel click on "Modules" - "MLE" - "MLE Moodle Config"

- $\quad$ Check that "Enable MLE-Moodle" is activated.

- Select the Mobile community course you created earlier and activate mobile communities

- $\quad$ Click on save

\section{Enabling Mobile Access}

- Log in as Admin

- Go to the front page and click on the button "Turn editing on" (upper right)

- Search for a new block called "blocks" and select "Mobile Access"

- Move the new "Mobile Access"-block where you want it to be

- In the new "Mobile access" block click on the last URL for the mobile browser access to open the page in your browser

- Be patient the first access to MLE-Moodle needs some time

Now you should see the MLE-Moodle front page, as you would see it on the mobile phone browser. If you click on the "Download"-button in the "Mobile access" block (back on the start-page of Moodle), you will be redirected to a download-server where you can download the mobile phone application, which is already pre-configured for your MLEMoodle server.

\section{Configuration Of Mle-Moodle}

\section{A. Configuring Browser Access}

- As Admin go to "Modules" - "MLE" - "MLE Browser Access"

- Put the URL as: http://yourdomain.com/moodle/blocks/mle/browser. php

\section{B. Configuring the Mobile Application (MLE Client)}

- As Admin go to "Modules" - "MLE" - "MLE Client: Installation"

If you do not want to use the mobile client, you can turn it off here, by deactivating the access.

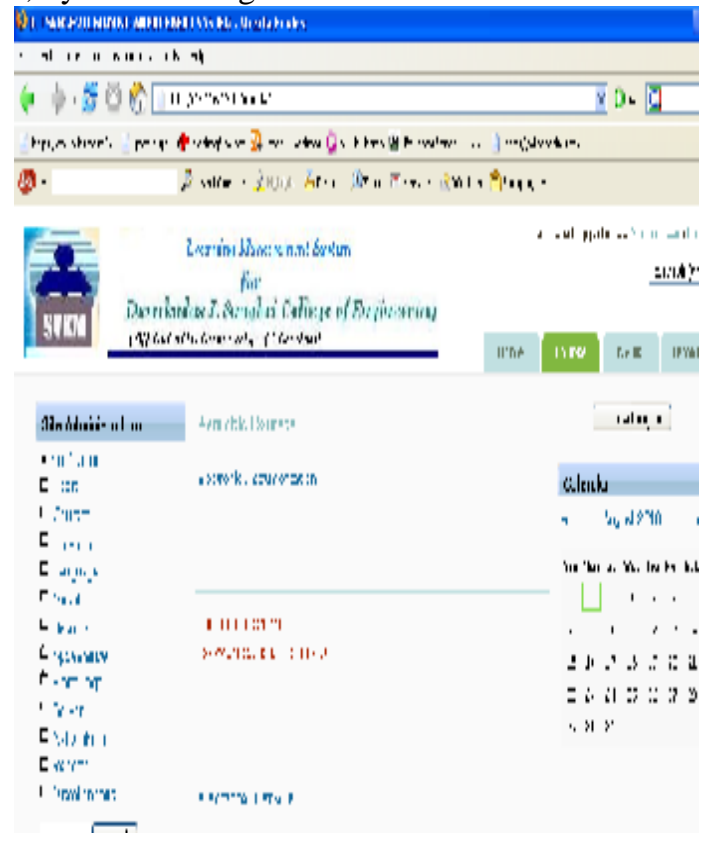

C. Configuring your Own Internal Download-Server

- To host the installation files on your own server, you must download the installation files first.

- The installation files are packed in a ZIP file or in a $7 \mathrm{z}$ file .You only need to download the language packages you really need.

- Furthermore you need to download the following file: mle_moodle.php

- Now you need to upload the files to your MLEMoodle server (MOODLE-DIR is the path to your MLE-Moodle installation):

- Copy the mle_moodle.php file to MOODLEDIR/blocks/mle/dwn/ (and overwrite the existing file).

- Now create a folder in MOODLEDIR/blocks/mle/dwn/ called "mle_moodle"

- Extract the downloaded installation packages and upload the content to this folder:

- MOODLEDIR/blocks/mle/dwn/mle_moodle/ in the folder MOODLEDIR/blocks/mle/dwn/mle moodle/ you should see now a new folder called "genvendor".

- As Admin go to "Modules" - "MLE" - "MLE Client: 
Installation"

- In "MLE installation files" enter now the full path to "MOODLE-DIR/blocks/mle/dwn/mle_moodle/"

- Now click on save at the bottom. You are now using your internal download-server and host your own installation files.
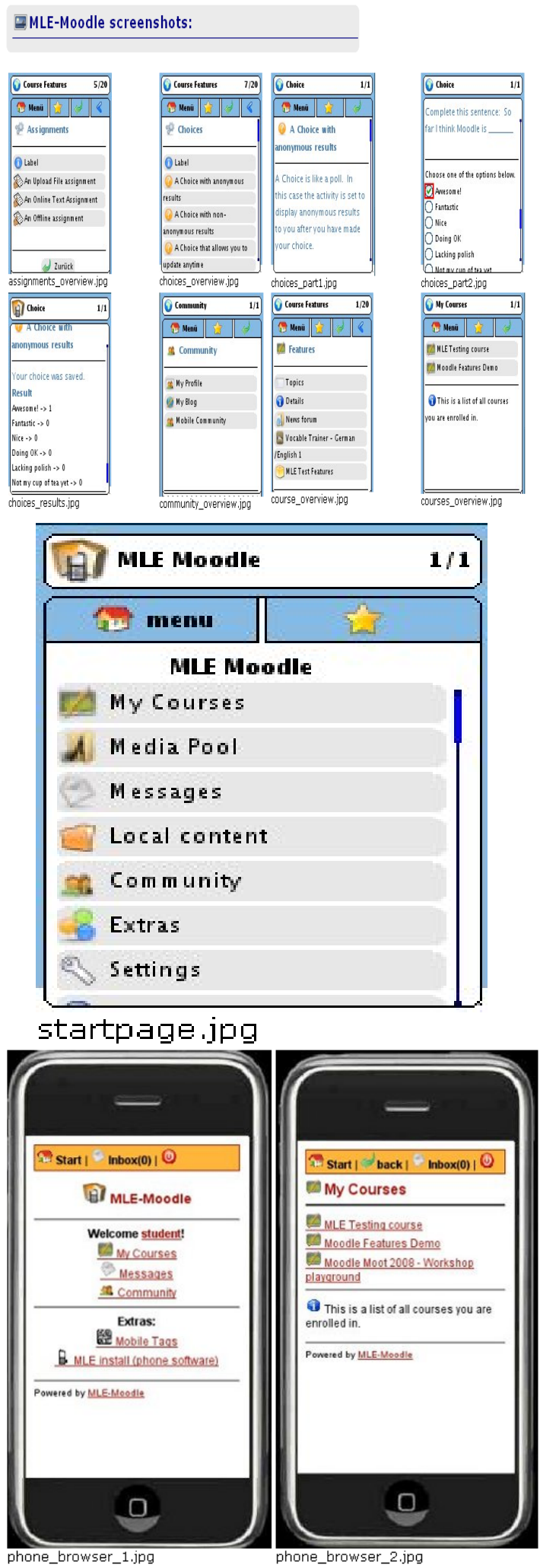

\section{CONCLUSION \& FUTURE WORK}

The increased use of ICT will force educational bodies to include ICT in the education process. The problems arising are the choice of tools and material creation. The Moodle environment with its simplicity and availability helps in this process. This paper focuses on the development of $\mathrm{M}$ Learning management tool in campus-wide environment using the MLE-Moodle as a Learning Management System with authentic \& proper security features. The project developed by us was run in order to evaluate the planning, design and execution of lectures using MLE- Moodle, Remote Laboratory Experiments and Lecture Web casting. Positive feedback from students has been received for using these tools as primary tools. Electronic slides, multimedia ematerial, the book, exercises, project tasks and selfevaluating questions as well as remote experiments have been available to students. The proposed system aims to extend the learning activities offered by a MLE-Moodle to support and enhance the ongoing learning process. The proposed system is intended for use by tutors and learners

\section{REFERENCES}

[1] A. Toth, P. Pentelenyi, and P. Toth, "Virtual Learning Aspects of Curriculum Development in Technical Teacher Training," in Proceedings of Intelligent Engineering Systems, 2006, IEEE, London, UK

[2] M. Dougiamas. Moodle. [Online]. Available: www.Moodle.org.

[3] M. Berry, An investigation of the effectiveness of Moodle in primary education, in Deputy Head. 2005, Haslemere.

[4] M. Z. Rela and R. Carvalho, "Work in Progress: Self Evaluation Through Monitored Peer Review Using the Moodle Platform," in Frontiers in Education Conference, 36th Annual, 2006. San Diego, CA: IEEE.

[5] K. Brandl, “Are you ready to Moodle” Language Learning/Technology, Washington, 2005, vol. 9, no. 2, pp. 16- 23.

[6] J. Itmazi, Flexible Learning Management System to Support Learning In the Traditional and Open Universities, 2005, Granada University, Spain.

[7] C. C. Su. "An Open Source Platform for Educators," in Proceedings of the Fifth IEEE Advanced Learning Technologies, 2005, IEEE Computer Society.

[8] EduTools. Course Management Systems. [Online]. Available: http://www.edutools.info/.

[9] S. N. Moodle, Transforming Learning Transforming Institutions, in Moodle Regional User.

[10] A. Chavan and S. Pavri, "Open-source learning management with moodle,” Linux Journal, vol. 128, no. 2, 2004.

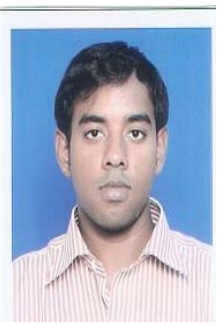

Ajay Arunachalam was working as Asst. Professor at Department of Computer Engineering, D.J .Sanghvi College of Engg, Vile Parle (W), Mumbai. He did his B.E (Computer Engg) from A.I.S.S.M.'S College of Engg, Pune University, Pune. And pursued his M.E (Computer Science \& Engineering) from Anna University, Chennai. His main research interests are in the area of FOSS in Educational Technology, Algorithms, Web Engineering. He has organized many national level conferences, workshops \& seminar and also presented \& published papers in National \& International Conferences.

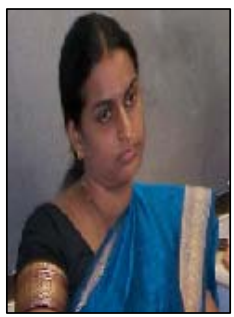

Lakshmi Kurup is an Asst. Professor at the Department of Computer Science and Engineering, D.J.Sanghvi College of Engg, Vile Parle (W), Mumbai. She did her B.E (Computer Engg) from Madurai Kamaraj University. Her main research interests are in the areas of Operating Systems, Advanced Computer Networks, and Theory of Computer Science etc. She has got nearly 3 years of Industrial experience and 2 years of teaching experience. She has organized national level conferences, workshops \& seminar 